\title{
Intelligent Design Based Neural Network Model for Measuring Analysis of the College Teachers' Teaching Ability
}

\author{
https://doi.org/10.3991/ijet.v15i15.15931 \\ Yihui Chen \\ Changchun Vocational Institute of Technology, Changchun, China \\ Mingli Yang $(\bowtie)$ \\ Jilin University, Changchun, China \\ Jilin Business and Technology College, Changchun, China \\ yangming_lesina.com
}

\begin{abstract}
The teaching ability of College Teachers is regarded as one of the core competencies and a critical indicator for measuring comprehensive strength for a college. However, its evaluation process is a highly complex system decision-making, for there are various factors that influence on the assessment of for the College Teachers' the teaching ability. The traditional methods have drawbacks of strong subjectivity, so they are difficult to correctly evaluate the teaching ability of College Teachers, resulting in decrease of measurement accuracy. Based on the analysis of the relevant factors, this paper presents an intelligent design based neural network model of discrete Hopfield for the measurement and analysis of College Teachers' teaching ability. Firstly, a Hopfield neural network model for the measure analysis of the teaching ability is established, and eleven measure analysis indexes are selected as input information of the Hopfield neural network model. Secondly, the College Teachers' teaching ability grades are chosen as the model output, then the input and output model based on the relationship among the self-learning abilities of neural network is established. Finally, the simulation experiment is obtained by using MATLAB. The simulation results show that the model has the characteristics of high efficiency, objectivity and fairness, which can meet the requirements of the measurement and analysis of College Teachers' teaching ability.
\end{abstract}

Keywords - College Teachers; Teaching Ability; Discrete Hopfield Neural Network Model; Intelligent Design; Evaluation Model.

\section{Introduction}

College Teachers' teaching ability reflects the comprehensive level of the college, which is the core competitiveness of college teachers [1]. The improvement of teaching ability is the key of college teachers' growth and developed, and can effectively drive 
the rapid development of the surrounding area and related industries. However, there are many factors that affect the teaching ability of university teachers, and it is difficult to use mathematical methods to express [2-3] these factors, especially when they are intertwined,. Traditional rating methods are based on human subjectivity, i.e. the overall evaluation of teaching ability level is concluded through the subjective evaluation for lots of aspects of teachers in this colleges and the comparison with that of teachers in other colleges. This method needs plenty of preparatory work with poor real-time, and is easily influenced by the personal factors, lack of objectivity. The different teams even have different evaluation results for the same college teachers when they use different scales [4-6].

Therefore, it is needed to establish a general evaluation model to realize the accurate and objective evaluation of teaching and researching ability. Artificial neural network is an intelligent system that is composed of the connection function and the connection weights based on a certain number of artificial neurons, which has the ability to deal with nonlinear and adaptive, and has been widely used in the field of artificial intelligence [7-10]. It can effectively solve the problem of traditional intelligent algorithms in dealing with non-structural information. Now the most widely used neural network model is the BP neural network, but it has defects in the aspects of convergence speed and local extremum, and requires a lot of training sample data [11-39]. In this paper, a new evaluation model based on the discrete Hopfield neural network is designed through analysis the characteristics of the evaluation for the teaching ability, then the model rules is established, verified and analyzed by using the data obtained from the teaching ability investigation in the similar 20 colleges.

\section{Evaluation Model of College Teachers' Teaching Ability}

The realization process of the neural network evaluation model of College Teachers' teaching ability is shown in Figure 1.

There are many factors that affect College Teachers' teaching ability. In this paper, 11 main factors are selected to constitute the evaluation index system, as is shown in Figure 2. 


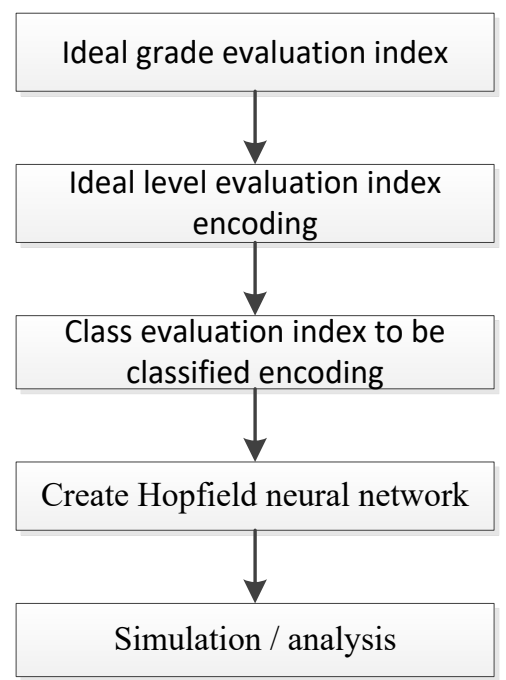

Fig. 1. The realization process of the neural network evaluation model of College Teachers' teaching ability

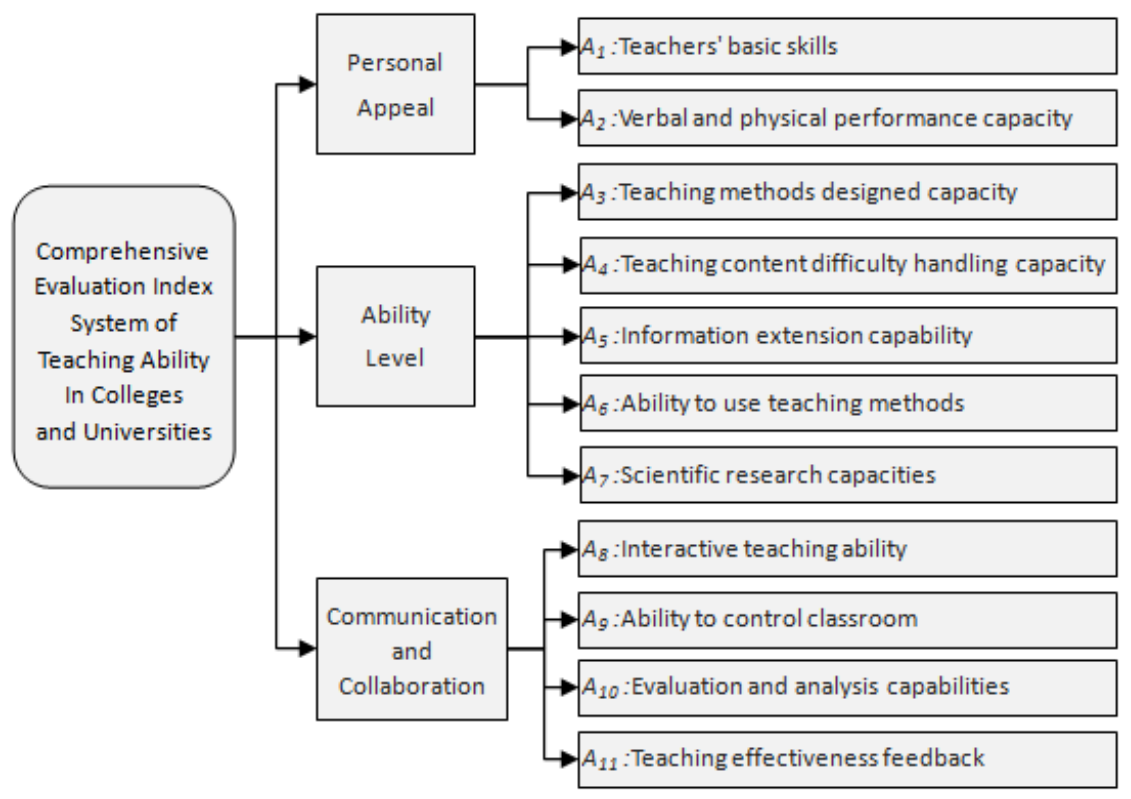

Fig. 2. Evaluation index system of College Teachers' teaching ability

Using percentile system for College Teachers' teaching ability, it can be divided into five levels: EXCELLENT (I), GOOD (II), COMMONLY(III), PASS (IV) and FAIL (V). Each level corresponds to a value range of the percentage, as is shown in table 1. 
Table 1. Percentage intervalcorresponding to evaluation level

\begin{tabular}{|l|c|c|}
\hline \multicolumn{1}{|c|}{ Scaling } & Percentage system & Group median \\
\hline EXCELLENT & $100 \sim 90$ & 95 \\
\hline GOOD & $80 \sim 90$ & 85 \\
\hline COMMONLY & $70 \sim 80$ & 75 \\
\hline PASS & $60 \sim 70$ & 65 \\
\hline FAIL & Below 60 & 30 \\
\hline
\end{tabular}

\section{Discrete Hopfield Neural Network}

Discrete Hopfield Neural Network is proposed in the 80's of last century, which is a new network model established on the basis of the traditional neural network theory, and can effectively simulate the biological brain's memory capacity. It is a single feedback neural network, using differential or differential equations to describe a dynamic process between the input and output [16-19].

In the first proposed Hopfield network, the output is only 1 and -1 , that is a two valued neural network, so it is also known as the discrete Hopfield neural network (Hopfield Neural Network Discrete, DHNN). DHNN is a kind of two valued neuron, which expresses the state of the neuron by the discrete value of the output.

\subsection{Network structure}

The network structure of DHNN is shown in Figure 3.

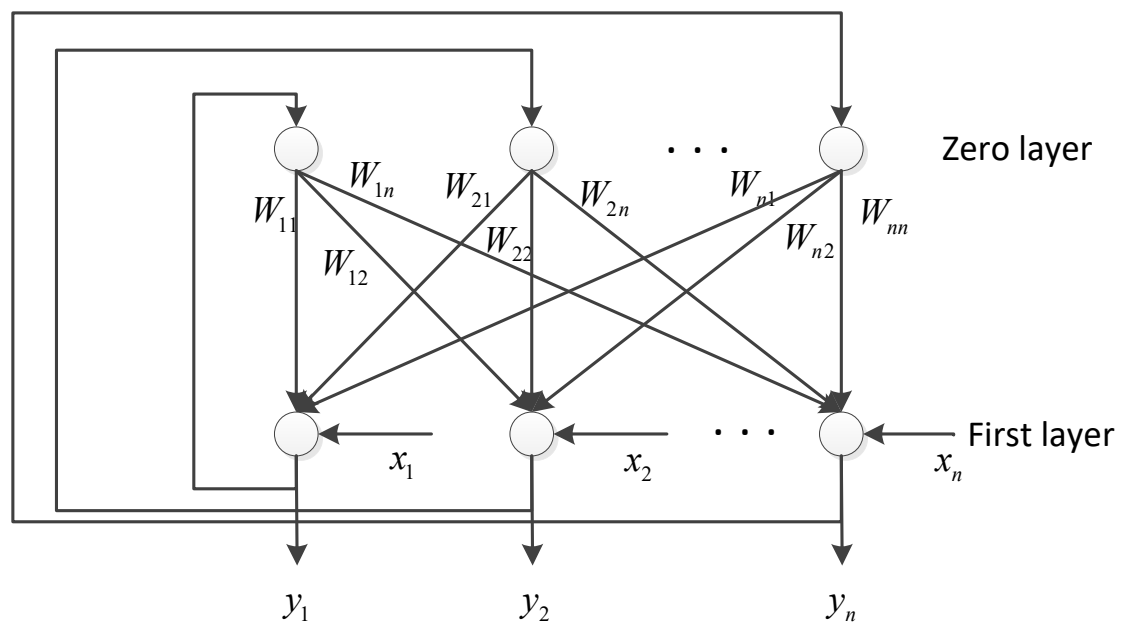

Fig. 3. Network structure of DHNN 
In figure 3, the zero layer of the network is the input unit, which does not have the computing power and is not the actual processing neuron; the neurons in first layer are the neurons for information processing, the information is processed by the function $\mathrm{f}$, and then it is outputted. The information processing function is a simple threshold decision function, that is, if the output information is greater than the set value, the output value is 1 , else -1 is outputted. By analyzing the structure of DHNN, it is a two-valued nonlinear dynamic system with multiple inputs and a threshold value. In this system, the steady state can be considered that it runs controlled by a certain energy function, the energy value is continuously reduced until meets the minimum.

For the two valued neuron model, the formula (1) is established.

$$
u_{i}=\sum_{i} w_{i j} y_{i}+x_{j}
$$

Here, ${ }^{x_{j}}$ is the external output, and meet the following conditions:

$$
\begin{aligned}
& y_{j}=1, \quad u_{j} \geq \theta_{j} \\
& y_{j}=-1, \quad u_{j}<\theta_{j}
\end{aligned}
$$

DHNN network status within dimension output information on time $\mathrm{t}$ is defined as:

$$
\begin{gathered}
y_{i}(t+1)=f\left[u_{i}(t)\right]=1, u_{j} \geq 0 \\
y_{i}(t+1)=f\left[u_{i}(t)\right]=-1, u_{j}<0 \\
u_{i}(t)=\sum_{i} w_{i j} y_{i}(t)+x_{j}-\theta_{j}
\end{gathered}
$$

When $\mathrm{i}$ equals to $\mathrm{j}$, if $w_{i j}$ is 0 , there is no data feedback to the input signal and this type of DHNN is called no-feedback neural network; else if $w_{i j}$ is not 0 , this DHNN is called the feedback neural network.

\subsection{Working methods of DHNN}

The way of DHNN works of s dynamic, which is the neuron changing process from its initial state with the changing direction of the system "energy" reduction. When the network is in a stable state, this state is the output.

In this paper, the DHNN is used in serial operation mode, that is only one neuron is in the working state at any time and its working process follows the formula (4), (5) and (6). The rest of the neurons keep their original state. The working neuron can be 
specified in advance or randomly determined, and the specific operation steps are as follows:

Step 1: Initialize the network according to the background of the teaching ability evaluation.

Step 2: Randomly select a neuron $i$.

Step 3: Compute the input $u_{i}(t)$ of neuron $i$.

Step 4: Compute the output $v_{i}(t+1)$ of neuron $i$, and other neurons continue to keep constant output.

Step 5: Determine whether the network is stable. If the network has reached a stable state or meets the conditions set in advance, the operation is over; otherwise, turn to Step 2 then go on.

The definition of steady state is: from a certain moment, the state of the network no longer changes, that is

$$
v(t+\Delta t)=v(t), \Delta t>0
$$

\subsection{Network stability}

In the above statement, the DHNN is a nonlinear dynamic system with multiple inputs and thresholds. The system runs in a specific energy function, so the energy value of the system continues to decrease. The system reaches a stable state when the energy value is the lowest. Coben and Gross berg present a sufficient condition for deciding if DHNN achieves steady state: If the weight matrix of the DHNN satisfies the following two formulas (8) \& (9), the network reaches stable.

$$
\begin{gathered}
w_{i j}=0, \quad i=j \\
w_{i j}=w_{j i}, \quad i \neq j
\end{gathered}
$$

\section{MATLAB Simulation and Analysis}

\subsection{Design Ideal Grade Evaluation Index}

In this paper, the corresponding relationship between the evaluation index data and the overall level of the teaching ability of the twenty university teachers is as shown in Table 2. 
Table 2. The evaluation index data and the overall level of College Teachers' teaching ability

\begin{tabular}{|c|c|c|c|c|c|c|c|c|c|c|c|c|}
\hline No & $\mathbf{A 1}$ & $\mathbf{A 2}$ & $\mathbf{A 3}$ & $\mathbf{A 4}$ & $\mathbf{A 5}$ & $\mathbf{A 6}$ & $\mathbf{A 7}$ & $\mathbf{A 8}$ & $\mathbf{A 9}$ & $\mathbf{A 1 0}$ & $\mathbf{A 1 1}$ & Level \\
\hline $\mathbf{1}$ & 74 & 86 & 84 & 63 & 87 & 76 & 88 & 78 & 95 & 80 & 83 & II \\
\hline $\mathbf{2}$ & 79 & 70 & 78 & 89 & 80 & 91 & 82 & 76 & 64 & 75 & 85 & II \\
\hline $\mathbf{3}$ & 99 & 91 & 88 & 93 & 88 & 99 & 95 & 94 & 93 & 94 & 95 & I \\
\hline $\mathbf{4}$ & 93 & 95 & 96 & 86 & 93 & 93 & 91 & 95 & 94 & 89 & 99 & I \\
\hline $\mathbf{5}$ & 88 & 95 & 95 & 95 & 90 & 97 & 92 & 86 & 97 & 97 & 95 & I \\
\hline $\mathbf{6}$ & 34 & 27 & 37 & 18 & 24 & 46 & 40 & 24 & 31 & 43 & 22 & V \\
\hline $\mathbf{7}$ & 95 & 88 & 98 & 92 & 89 & 98 & 97 & 85 & 94 & 87 & 89 & I \\
\hline $\mathbf{8}$ & 39 & 42 & 53 & 60 & 46 & 59 & 55 & 44 & 50 & 49 & 55 & IV \\
\hline $\mathbf{9}$ & 17 & 43 & 34 & 36 & 24 & 37 & 22 & 35 & 35 & 32 & 40 & V \\
\hline $\mathbf{1 0}$ & 68 & 64 & 64 & 66 & 61 & 58 & 63 & 67 & 67 & 62 & 66 & III \\
\hline $\mathbf{1 1}$ & 25 & 36 & 47 & 29 & 16 & 31 & 35 & 11 & 23 & 37 & 31 & V \\
\hline $\mathbf{1 2}$ & 85 & 79 & 73 & 76 & 71 & 85 & 76 & 65 & 83 & 87 & 76 & II \\
\hline $\mathbf{1 3}$ & 54 & 45 & 49 & 56 & 53 & 38 & 41 & 46 & 53 & 57 & 48 & IV \\
\hline $\mathbf{1 4}$ & 94 & 97 & 92 & 94 & 86 & 96 & 99 & 91 & 87 & 92 & 96 & I \\
\hline $\mathbf{1 5}$ & 45 & 57 & 57 & 43 & 60 & 56 & 48 & 57 & 56 & 44 & 44 & IV \\
\hline $\mathbf{1 6}$ & 36 & 22 & 18 & 25 & 36 & 26 & 31 & 26 & 39 & 20 & 27 & V \\
\hline $\mathbf{1 7}$ & 59 & 64 & 64 & 65 & 69 & 71 & 66 & 63 & 71 & 73 & 66 & III \\
\hline $\mathbf{1 8}$ & 74 & 83 & 97 & 76 & 82 & 88 & 78 & 81 & 90 & 74 & 88 & II \\
\hline $\mathbf{1 9}$ & 68 & 72 & 68 & 62 & 63 & 63 & 71 & 69 & 75 & 61 & 69 & III \\
\hline $\mathbf{2 0}$ & 62 & 63 & 64 & 55 & 65 & 70 & 74 & 62 & 64 & 68 & 63 & III \\
\hline
\end{tabular}

The average value of the evaluation index data at each level is considered as the reference value, which is the equilibrium point of the network, as shown in Table 3.

Table 3. 5 levels of ideal evaluation index

\begin{tabular}{|c|c|c|c|c|c|c|c|c|c|c|c|}
\hline $\begin{array}{c}\text { Leve } \\
\text { I }\end{array}$ & A1 & A2 & A3 & A4 & A5 & A6 & A7 & A8 & A9 & A10 & A11 \\
\hline I & 94 & 93 & 94 & 92 & 89 & 97 & 95 & 90 & 93 & 92 & 95 \\
\hline II & 78 & 77 & 83 & 76 & 80 & 85 & 81 & 75 & 83 & 79 & 83 \\
\hline III & 64 & 66 & 66 & 61 & 65 & 66 & 68 & 65 & 69 & 66 & 66 \\
\hline IV & 46 & 48 & 53 & 53 & 53 & 51 & 48 & 49 & 53 & 50 & 49 \\
\hline V & 28 & 32 & 34 & 27 & 25 & 35 & 32 & 24 & 32 & 33 & 30 \\
\hline
\end{tabular}




\subsection{Ideal code of grade evaluation index}

In order to realize the mapping of evaluation index to the neuron state, the index coding is needed. When the corresponding data value of the neuron is greater than or equal to the reference value, the state is "1", whereas the opposite is "- 1 ". Under ideal conditions, the coding form of the 5 level evaluation indexes is shown in Figure 4, here, "•"indicates that the neuron state is "1", which is greater than or equal to the corresponding level of the reference value, otherwise,"॰" is used.

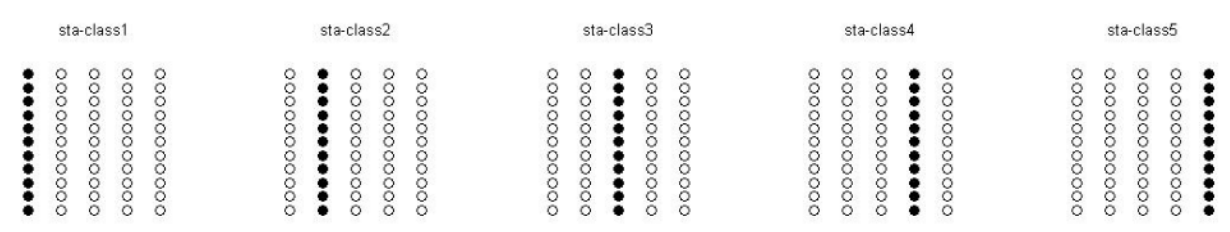

Fig. 4. Ideal 5 level evaluation index code

\subsection{Evaluation index code for classification}

The related unclassified data of 5 College Teachers is shown in Table 4; the corresponding coding is shown in Figure 5.

Table 4. Evaluation index data of College Teachers' teaching ability to be classified

\begin{tabular}{|c|c|c|c|c|c|c|c|c|c|c|c|c|}
\hline Sequence & A1 & \multicolumn{1}{c}{ A2 } & \multicolumn{1}{c}{ A3 } & \multicolumn{1}{c}{ A4 } & A5 & A6 & A7 & A8 & A9 & A10 & A11 \\
\hline $\mathbf{1}$ & 97 & 91 & 87 & 87 & 91 & 89 & 96 & 74 & 99 & 93 & 98 \\
\hline $\mathbf{2}$ & 71 & 87 & 77 & 80 & 94 & 81 & 91 & 78 & 85 & 84 & 84 \\
\hline $\mathbf{3}$ & 61 & 74 & 70 & 65 & 55 & 76 & 78 & 81 & 70 & 74 & 65 \\
\hline $\mathbf{4}$ & 56 & 58 & 43 & 79 & 56 & 75 & 59 & 46 & 57 & 42 & 56 \\
\hline $\mathbf{5}$ & 21 & 37 & 44 & 23 & 22 & 39 & 42 & 34 & 22 & 45 & 36 \\
\hline
\end{tabular}

req-sim1

req-sim2

req-sim3

req-sim4

req-sim5
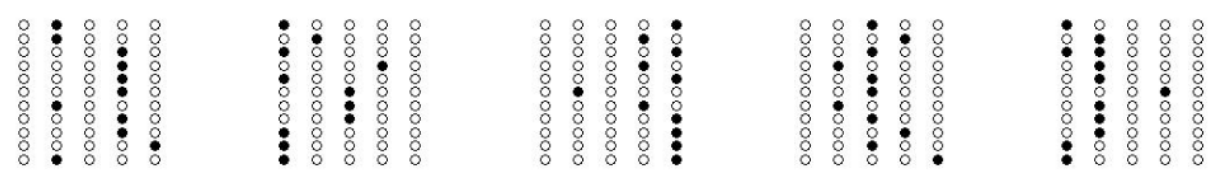

Fig. 5. The source code of College Teachers' grade evaluation index data

\subsection{Creating network and simulation}

In MATLAB, the neural network toolbox is used to provide the function to create the Hopfield neural network. The encoded data to be classified as the input for the network analysis, after a number of iterations of learning, the network reached a stable state, and the results as is shown in Figure 6. 


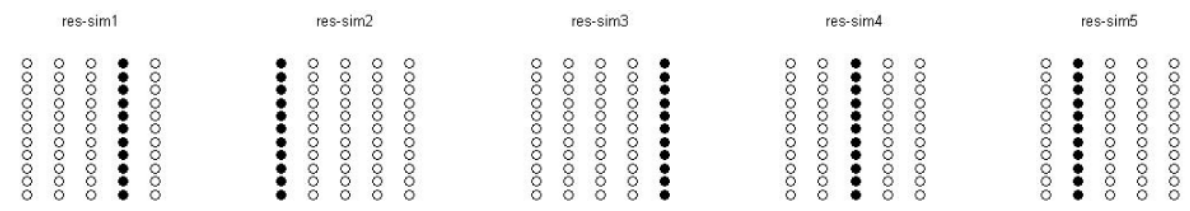

Fig. 6. Experimental simulation results

Comparing the simulation results with the data in Figure 4 and 5, we can draw a conclusion that the evaluation model based on DHNN in this paper is able to objectively, accurately, fairly and effectively evaluate for the College Teachers' teaching ability and to reach pre-goal set.

\section{Conclusion}

In the view of complexity for the evaluation analysis of the College Teachers' teaching ability, this paper researched and analyzed the evaluation index system, and proposed a new intelligent design based DHNN model for measuring analysis of the College Teachers' teaching ability. Through analysis and simulation, it is indicated that the proposed model not only can be used to properly evaluate the College Teachers' teaching ability by education authorities and enterprises, also can be used for the teachers to give self-appraisal and improve the shortcomings in the comprehensive teaching ability to enhance self-quality. In addition, this model has good applicability, because it can be refined in accordance with the requirements of the evaluation index, in order to achieve the requirements of the measurement analysis.

\section{Acknowledgement}

This work was supported by the following projects: the "2018 plan" science and technology research projects of Education Department of Jilin Business and Technology College, with the number: K20180006 and the name: "Measurement, Analysis and Modeling of Big Data in Improving Tourism Crisis Early Warning Ability".

\section{$7 \quad$ Reference}

[1] Saaty, T. L. (1996). The Analytic Hierarchy Process. New York N.Y. McGraw Hill, 1980, reprinted by RWS Publications, Pittsburgh.

[2] Liu, S. M., Gao, H. P. (1993), The Method on Multi-input/Multi-output Fuzzy System Decoupling, Journal of Fuzzy Mathematics, 1: 2-6

[3] Hills, P. (1995). PREST Experience of Evaluation, Scientomentrics. 34: 125-172

[4] CrisKobryn. (2000). Modeling Components and Frameworks with UML, Dr.Dobb's Journal: Software Tools for the Professional Programmer, 43: 52-55 
[5] Lei, Y. (2007). The Application of the Fuzzy Comprehensive Evaluation in the Personal Assessment, SCI-TECH INFORMATION DEVELOPMENT \& ECONOMY, 17: 259-264

[6] Sun, J. W., Zhao, M., Liu M. (2002). The Design Method of a Teacher Electronic File Management Information System. Yang Deli e. t. Advances in Theories and Application of Electronic Commerce Research, Liaoning Dalian, Dalian: Dalian College of Technology Press, 444-451. https://doi.org/10.25103/jestr.071.04

[7] Thomas, L. S., Luis, G. V. (1994). Decision caking in Economic, Political, Social and Technological Environments. College of Pittsburgh.

[8] Berrezzek, F., Khelil, K., Bouadjila, T. (2019). Efficient wind speed forecasting using discrete wavelet transform and artificial neural networks. Revue d'Intelligence Artificielle, 33: 447-452. https://doi.org/10.18280/ria.330607

[9] Yang, M. L., Chen, Y. H. (2010). The Research of Evaluation System Model of Web SelfLearning Based on AHP Method and The System Implement. The Proceeding of ICCASM, 10: 253-256. https://doi.org/10.1109/iccasm.2010.5622805

[10] Soliman, G.M.A., Abou-El-Enien, T.H.M. (2019). Terrorism prediction using artificial neural network. Revue d'Intelligence Artificielle, 33: 81-87. https://doi.org/10.18280/ria.3 $\underline{30201}$

[11] Yang, M. L., Chen, Y. H. (2012). Image Processing System Based on the ARM Embedded System Architecture. The Proceeding of GCN, 719-725.

[12] Cheng, X., Zhao, C.Y. (2019). Prediction of tourist consumption based on Bayesian network and big data. Ingénierie des Systèmes d'Information, 24: 491-496. https://doi.org/10.18280/ $\underline{\text { isi. } 240505}$

[13] Batle, J., Ciftja, O., Naseri, M., Ghoranneviss, M., Farouk, A., Elhoseny, M. (2017). Equilibrium and uniform charge distribution of a classical two-dimensional system of point charges with hard-wall confinement. Physica Scripta, 92: 055801 https://doi.org/10.1088/1 402-4896/aa6630

[14] Sun, D. S. (2008). Research on principal component analysis and factor analysis and application in software, Statistics and Decision, 13: 153-155.

[15] Huang, Q. H.., Wei L. Y., Luo, Q. L. (2012). Independent faculty teaching and research capabilities status and promotion strategy, Value Engineering, 26: 223-225.

[16] Zhou, N. R., Liang, X. R., Zhou, Z. H., Farouk, A. (2016). Relay selection scheme for amplify-and-forward cooperative communication system with artificial noise. Security and Communication Networks, 9: 1398-1404. https://doi.org/10.1002/sec.1425

[17] Batle, J., Ooi, C. R., Farouk, A., Abdalla, S. (2016). Nonlocality in pure and mixed n-qubit X states. Quantum Information Processing, 15: 1553-1567. https://doi.org/10.1007/s11128-01 $\underline{5-1216-5}$

[18] Effati, S., Mansoori, A., Eshaghnezhad, M. (2015). An efficient projection neural network for solving bilinear programming problems. Neurocomputing, 168: 1188-1197. https://doi. org/10.1016/j.neucom.2015.05.003

[19] Cheng, C., Cheng, X. S., Dai, N., Jiang, X. T., Sun, Y. C., Li, W. W. (2015). Prediction of facial deformation after complete denture prosthesis using BP neural network. Computers in Biology and Medicine, 66: 103-112. https://doi.org/10.1016/j.compbiomed.2015.08.018

[20] Wang, H. S., Wang, Y. N., Wang, Y. C. (2013). Cost estimation of plastic injection molding parts through integration of PSO and BP neural network. Expert Systems with Applications, 40: 418-428. https://doi.org/10.1016/j.eswa.2012.01.166

[21] Abulkasim, H., Farouk, A., Alsuqaih, H., Hamdan, W., Hamad, S., Ghose, S. (2018). Improving the security of quantum key agreement protocols with single photon in both polarization and spatial-mode degrees of freedom. Quantum Information Processing, 17: 316. https://doi.org/10.1007/s11128-018-2091-7 
[22] Marat. A., Mehmet, O. F. (2014). Generation of cyclic/toroidal chaos by Hopfield neural networks. Neurocomputing, 145: 230-239. https://doi.org/10.1016/j.neucom.2014.05.038

[23] Hu. Y. Z. (2014). A class of stochastic Hopfield neural networks with expectations in coefficients. Neurocomputing, 141: 188-193. https://doi.org/10.1016/j.neucom.2014.03.021

[24] Nagata, K., Nakamura, T., Geurdes, H., Batle, J., Abdalla, S., Farouk, A. (2018). Creating very true quantum algorithms for quantum energy based computing. International Journal of Theoretical Physics, 57: 973-980. https://doi.org/10.1007/s10773-017-3630-1

[25] Sun, F., Jiang, T., Li, X., Fan, Y. (2013). An intelligent prognostic method for SSADT based on SVM, Chemical Engineering Transactions, 33: 103-108.

[26] Yao, J., Luo, R., Liu, Q., Peng, C., Jia, Y. (2013). Study on the application of the shock model in forecasting residual life of $\mathrm{CNC}$ system, Chemical Engineering Transactions, 33: 97-102

[27] Liu, J. M., Liu, Y. H., Cheng, J. P., Feng, F. Z. (2013). Extraction of gear fault feature based on the envelope and time-frequency image of $\mathrm{s}$ transformation, Chemical Engineering Transactions, 33: 55-60

[28] Grall-Maes, E., Wang, X., Beauseroy, P. (2013). Tuning the covariate influence in a gamma process clustering algorithm, Chemical Engineering Transactions, 33: 49-54

[29] Lamoureux, B., Mechbal, N., Masse, J.R. (2013). Numerical key performance indicators for the validation of phm health indicators with application to a hydraulic actuation system, Chemical Engineering Transactions, 33: 43-48

[30] Yang, D., Hu, Z., Yang, Y., He, X. (2013). Weak magnetic memory signal denoising based on cascaded singularvalue decomposition, Chemical Engineering Transactions, 33: 37-42

[31] Qin, Y. P., Zheng, C. F. (2019). A backpropagation neural network-based flexural-tensile strength prediction model for asphalt mixture in cold regions under cyclic thermal stress. Mathematical Modelling of Engineering Problems, 6: 433-436. https://doi.org/10.18280/m $\underline{\text { mep. } 060315}$

[32] Lakshmipathi Anantha, N., Battula, B. P. (2018). Deep convolutional neural networks for product recommendation. Ingénierie des Systèmes d'Information, 23: 161-172. https://doi. org/10.3166/isi.23.6.161-172

[33] Wu, W., Huang, L., Du, R.H. (2020). Simultaneous Optimization of Vehicle Arrival Time and Signal Timings within a Connected Vehicle Environment. Sensors, 20: 191. https://doi. org/10.3390/s20010191

[34] Bin, S., Sun, G. (2020). Optimal Energy Resources Allocation Method of Wireless Sensor Networks for Intelligent Railway Systems. Sensors, 20: 482. https://doi.org/10.3390/s2002 $\underline{0482}$

[35] Wu, W., Zhang, F., Liu, W., Lodewijks, G. (2020). Modelling the traffic in a mixed network with autonomous-driving expressways and non-autonomous local streets. Transportation Research Part E: Logistics and Transportation Review, 134: 101855. https://doi.org/10.101 6/j.tre.2020.101855

[36] Neelapu, R., Devi, G. L., Rao, K. S. (2018). Deep learning based conventional neural network architecture for medical image classification. Traitement du Signal, 35: 169-182. https://doi.org/10.3166/ts.35.169-182

[37] Choubey, H., Pandey, A. (2018). Classification of healthy, inter-ictal and seizure signal using various classification techniques. Traitement du Signal, 35: 75-84. https://doi.org/10. $\underline{3166 / t s .35 .75-84}$

[38] Sukhbaatar, O., Usagawa, T., Choimaa, L. (2019). An artificial neural network based early prediction of failure-prone students in blended learning course, International Journal of Emerging Technologies in Learning, 14: 77-92. https://doi.org/10.3991/ijet.v14i19.10366 
[39] Liu, W. (2019). An improved back-propagation neural network for the prediction of college students' English performance, International Journal of Emerging Technologies in Learning, 14: 130-142. https://doi.org/10.3991/ijet.v14i16.11187

\section{Authors}

Chen Yihui is a researcher and associate professor in the school of computer science of Changchun vocational and technical college, Changchun, Jilin, China. He mainly works in computer application technology, mainly in software engineering, blockchain technology, big data analysis, etc. chenyi_h@sina.com

Yang Mingli is a researcher and associate professor of the Institute of technology of Jilin University of business, Changchun, Jilin, China. Her main fields of work are computer science and technology, artificial intelligence, big data analysis and processing, graphics and image processing, etc.

Article submitted 2020-06-05. Resubmitted 2020-07-10. Final acceptance 2020-07-11. Final version published as submitted by the authors. 